Article

\title{
Comparison of a Novel Miniaturized Screening Device with Büchi B290 Mini Spray-Dryer for the Development of Spray-Dried Solid Dispersions (SDSDs)
}

\author{
Aymeric Ousset ${ }^{1}{ }^{(1)}$, Joke Meeus ${ }^{2}$, Florent Robin ${ }^{2}$, Martin Alexander Schubert ${ }^{2}$, \\ Pascal Somville ${ }^{2}$ and Kalliopi Dodou ${ }^{1, * \text { (D) }}$ \\ 1 School of Pharmacy and Pharmaceutical Sciences, Faculty of Health Sciences and Wellbeing, University of \\ Sunderland, Sunderland SR13SD, UK; aymeric.ousset@gmail.com \\ 2 UCB Pharma S.A., Product Development, B-1420 Braine l'Alleud, Belgium; joke.meeus.1@gmail.com (J.M.); \\ Florent.Robin@ucb.com (F.R.); Martin-Alexander.Schubert@gmx.net (M.A.S.); \\ Pascal.Somville@ucb.com (P.S.) \\ * Correspondence: kalliopi.dodou@sunderland.ac.uk; Tel.: +44-(0191)-515-2503
}

Received: 2 July 2018; Accepted: 13 August 2018; Published: 16 August 2018

\begin{abstract}
Spray-drying is an increasingly popular technology for the production of amorphous solid dispersions (ASDs) in the pharmaceutical industry that is used in the early evaluation and industrial production of formulations. Efficient screening of ASD in the earliest phase of drug development is therefore critical. A novel miniaturized atomization equipment for screening spray-dried solid dispersions (SDSDs) in early formulation and process development was developed. An in-depth comparison between the equipment/process parameters and performance of our novel screening device and a laboratory Büchi B290 mini spray-dryer was performed. Equipment qualification was conducted by comparing the particle/powder attributes, i.e., miscibility/solid state, residual solvent, and morphological properties of binary SDSDs of itraconazole prepared at both screening and laboratory scales. The operating mode of the miniaturized device was able to reproduce similar process conditions / parameters (e.g., outlet temperature $\left(\mathrm{T}_{\text {out }}\right)$ ) and to provide particles with similar drug-polymer miscibility and morphology as laboratory-scale SDSDs. These findings confirm that the design and operation of this novel screening equipment mimic the microscale evaporation mechanism of a larger spray-dryer. The miniaturized spray-dryer was therefore able to provide a rational prediction of adequate polymer and drug loading (DL) for SDSD development while reducing active pharmaceutical ingredient (API) consumption by a factor of 120 and cycle time by a factor of 4 .
\end{abstract}

Keywords: amorphous solid dispersions; spray-dryer; screening; miniaturization; downscaling; miscibility; polymers

\section{Introduction}

Spray-drying is a widely used process in the pharmaceutical industry to transform a solution, suspension, or emulsion into a powder [1,2]. The operation mode of spray-drying can be described by four steps: atomization of the feed solution into fine droplets, contact with hot drying gas, fast solvent evaporation, and separation of dried particles from drying gas [3]. Droplet-air contact via a cocurrent configuration where an atomized solution and drying gas are flowing in the same direction is the most prevalent method in the pharmaceutical industry. This configuration allows for the processing of heat-sensitive compounds because exposure to high temperatures is very limited due to solvent 
evaporation cooling [4]. Additionally, spray-drying is a continuous process that offers the advantages of tailoring both particle attributes (e.g., particle size, specific surface area, morphology, and residual solvent) and powder properties (e.g., flowability, compressibility, and bulk density) [5,6].

The use of spray-drying has been particularly suitable for the preparation of amorphous solid dispersions (ASDs) at the industrial scale [7]. This can be explained on the basis that the rapid solvent evaporation that occurs during the process minimizes the time window for phase separation and recrystallization and favors the formation of an amorphous system [8]. Manufacturing of stable ASDs is currently one of the most investigated formulation strategies in drug delivery design to overcome solubility challenges of class II and class IV drugs (according to the biopharmaceutics classification system) [9]. The term ASD refers to the formulation technique which consists of the drug amorphization and its dispersion into a hydrophilic polymeric (amorphous) carrier [10]. Nevertheless, inappropriate carrier selection, drug loading (DL), and process conditions/methods can engender phase separation/drug recrystallization after processing that would lead to a reduction in ASD performance [11,12]. In contrast, the formation of a single amorphous phase system, also referred to as "glass solution", where the amorphous drug is molecularly dispersed into the polymeric chain represents the most favorable ASD system in terms of physical stability and solubility enhancement [13].

Spray-drying is a scalable process that finds application at various stages of active pharmaceutical ingredient (API) development, from the early evaluation of the formulation to pilot size scale-up and production at a further industrial scale where batches of up to several tons per day can be achieved. Therefore, the prediction of the properties and performance of spray-dried solid dispersions (SDSDs) prepared during pilot/industrial production is of major interest from the earliest stages of drug development. In this regard, several small-scale screening methods such as film casting, quench cooling, or spin coating have been developed to predict the properties of SDSDs and therefore select the appropriate carrier and DL for the manufacturing of robust SDSDs [14,15]. Although these standard methodologies only require a minimal drug amount, their lack of correlation with the operating conditions of regular spray-drying limits their applicability and usefulness [16,17]. Moreover, although the application of laboratory spray-dryers can be particularly suitable to support preclinical to early stage clinical activities, their use remains limited during screening phases when a very limited amount of API is available for experimental work [18].

Therefore, given that spray-drying is a complex technology where the interplay of process parameters and process conditions (e.g., inlet temperature, drying airflow, feed rate, atomizing airflow, and nozzle configuration) is known to influence the droplet/particle formation $[19,20]$ and thereby the particle/powder properties [21], there is a necessity to develop a novel small-scale screening system that would be representative of the operating mode and the process conditions of a regular spray-dryer. Efforts to miniaturize and mimic existing manufacturing processes are currently a hot topic in the pharmaceutical industry [22]. As such, the objective of this paper was to develop a robust, cost-effective, and efficient miniaturized screening device mimicking a standard laboratory spray-dryer to provide an accurate prediction of SDSDs properties. The device's design was aimed to respect the formulation development constraints in a preformulation context such as reduced time and very limited API availability for screening purposes.

In this paper, first, the operational equipment parameters and design of our miniaturized device was compared to laboratory-scale Büchi B290 mini spray-dryer. Then, the performance of both equipment in terms of API consumption, production rate, yield, and output parameters were compared in order to assess their capability to operate in a screening environment. Finally, the qualification of this novel screening device was conducted with the production of 20:80, 40:60, 60:40, and 80:20 (w/w) itraconazole binary ASDs prepared with a set of polymers commonly tested during preformulation screening phases (e.g., HPMCP HP50, HPMCAS-LF, PVPVA, PVPK30, Soluplus, Eudragit L100, and Eudragit L100-55). Particle/powder attributes of itraconazole SDSDs generated at both screening and laboratory scales were compared in terms of morphological properties, solid state, drug-polymer miscibility, and moisture/residual solvent content. The investigated spray-dried material attributes 
would allow insight on how the process conditions and design of both systems impact the droplet evaporation kinetic and particle formation process of SDSDs.

\section{Materials and Methods}

\subsection{Materials}

Crystalline itraconazole was purchased from SRIS Pharmaceuticals (Hyderabad, India). Hydroxypropylmethylcellulose phthalate (HPMCP HP50) and hydroxypropylmethylcellulose acetate succinate fine grade (HPMCAS-LF) were obtained from Shin-Etsu (Tokyo, Japan). Polyvinylpyrrolidone (PVPK30) was purchased from VWR (Radnor, PA, USA), copolymer of $N$-vinyl-2-pyrrolidone and vinyl acetate (PVPVA) was obtained from Ashland (Covington, KY, USA), and copolymer of polyvinyl caprolactam-polyvinyl acetate-polyethylene glycol graft copolymer (Soluplus) was donated by BASF (Ludwigshafen am Rhein, Germany). Copolymer of methacrylic acid and methyl methacrylate 1:1 (Eudragit L100) and copolymer of methacrylic acid and ethyl acrylate copolymer 1:1 (Eudragit L100-55) were donated by Evonik (Essen, Germany). The solvents used were of analytical or HPLC grade.

\subsection{Methods}

\subsubsection{Design of the Novel Miniaturized Atomization Device}

The atomization of the feed solution was achieved by using a bifluid 0.15-mm Infinity Two in One airbrush nozzle (Harder \& Steenbeck, Norderstedt, Germany). The airbrush used here is commonly used for painting applications and allows the generation of a fine spray. The air nozzle pressure was fixed at 1.5 bars to disperse the feed solution and create a spray. Contrary to a laboratory spray-dryer, where a peristaltic pump is generally used to transfer the feed solution to the nozzle, in the current miniaturized design, the relatively low volume of feed solution $(0.25-1 \mathrm{~mL})$ was spread into the reservoir of the airbrush. In this configuration, the feed solution was directly available to the nozzle, which allowed avoiding the presence of dead volume as it occurs in the tubing of a standard pump and therefore minimized the loss of material during the process. The amount of feed solution brought to the nozzle was manually controlled by the operator by adjusting the amplitude of the airbrush needle. About $1 \mathrm{~mL}$ of feed solution was gradually atomized in a time period of $30 \mathrm{~s}$. The same procedure was reproduced during all experiments.

As shown in Figure 1, the proposed miniaturized equipment was comprised of seven parts. Part I represented the inox holder on top of the device in which the nozzle was disposed during processing. Part II was an inox tubing that serves as an inlet for drying air supply. Droplet drying was achieved using a drying airflow rate of $20 \mathrm{~L} / \mathrm{min}$ at $100{ }^{\circ} \mathrm{C}$ generated using an Aoyue int $852 \mathrm{SMD}$ rework station (Aoyue, Zhongshan, China). Part III was a 3D-printed system which ensured sealing on top of the system and favors the droplet-air contact through a cocurrent configuration. Part IV consisted of bottom sawed glass tube of $15 \mathrm{~cm}$ (VWR, Heverlee, Belgium) and was used as the drying chamber of the system in which solvent evaporation and particle formation took place. Once drying of the droplets was achieved, the flow of dried particles was transported to the bottom of the drying chamber and passed through a 3D-printed funnel (Part V). Separation of dried particles from the exhaust airflow was achieved in contact with Part VI, typically a standard aluminium differential scanning calorimetry (DSC) pan (TA Instruments, Leatherhead, UK) attached on the center of a 3D-printed pan holder (Part VII). Powder was collected into Part VI while air was removed from the interstices of Part VII and evacuated at the bottom of the chamber. Regarding safety and cleaning considerations, the materials chosen in the equipment design were resistant to many organic solvents, cleaning agents, and were compatible with the excipients and drug used. 


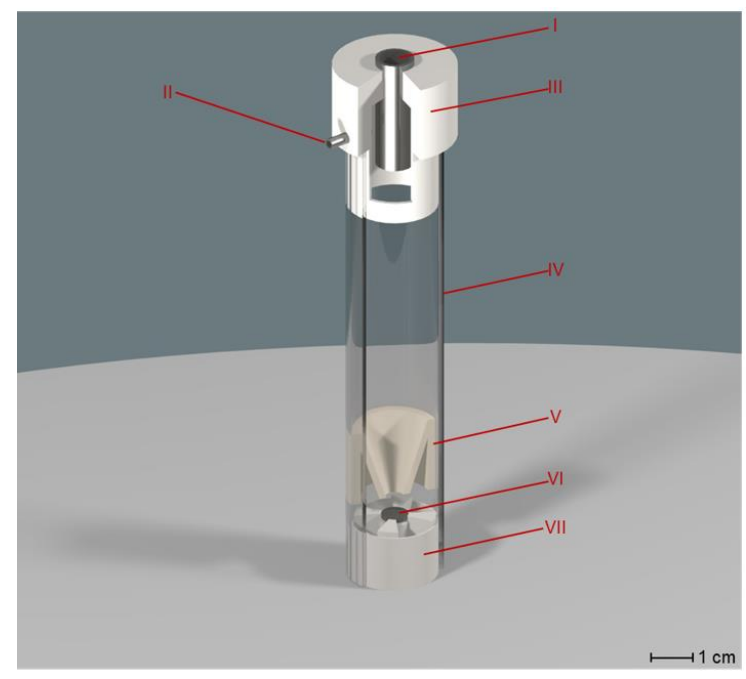

Figure 1. Design and layout of miniaturized atomization device: Part I: inox nozzle holder spare parts; Part II: inlet for drying air; Part III: 3D-printed system (Delrin ${ }^{\circledR}$ (Polyoxymethylene)) ensuring sealing of the system and cocurrent configuration contact between air and droplets; Part IV: drying chamber; Part V: 3D-printed funnel (Acrylonitrile butadiene styrene (ABS)) for air stream adjustment; Part VI: powder collection in differential scanning calorimetry (DSC) aluminium pan for powder collection; Part VII: perforated 3D-printed DSC pan holder (ABS).

\subsubsection{Performance Qualification of the Novel Device}

In order to assess the performance of the novel equipment, binary ASDs of itraconazole were produced at $20 \%, 40 \%, 60 \%$, and $80 \%(w / w)$ DL with a large range of polymers (HPMCP HP50, HPMCAS-LF, PVPVA, PVPK30, Soluplus, Eudragit L100, and Eudragit L100-55) commonly used in the screening phases of ASD in the pharmaceutical industry. Drug and polymer solutions were prepared in a binary solvent mixture of Dichloromethane (DCM)/Ethanol (EtOH) 2:1 $(v / v)$ at 5\% $(w / v)$ to be representative of feed solutions commonly used at laboratory scale. After processing, a minimum amount of $2 \mathrm{mg}$ of powder was collected to ensure that sufficient material was available for analytical characterization.

\subsubsection{Manufacturing Method of Reference-Spray-Dryer}

Productions of binary SDSD were conducted using the laboratory-scale Büchi B290 mini spray-dryer (Büchi Labortechnik AG, Flawil, Switzerland). The inlet temperature was fixed at $65^{\circ} \mathrm{C}$ and the drying airflow rate at $35 \mathrm{~m}^{3} / \mathrm{h}$. Feed solution atomization was performed using a $0.7-\mathrm{mm}$ bifluid nozzle and an atomizing airflow of $9 \mathrm{~L} / \mathrm{min}$ while the solution feed rate was maintained at $4 \mathrm{~mL} / \mathrm{min}$. During the process, the system was operating in a closed recycling loop configuration.

\subsubsection{Operational and Performance Equipment Parameters}

Yield

Yield (\%) was calculated as the ratio between the amount of particles collected in the DSC pan or in the collector at miniaturized and laboratory scale, respectively, and the total amount of solid dissolved in the feed solution.

\section{Equipment Parameters Including Dimensionless Parameter}

- Atomizing-airflow-to-liquid-feed-flow-rate ratio was calculated using both our miniaturized device and laboratory-scale Büchi B290 mini spray-dryer. Density $(\rho)$ values of DCM $\left(\rho_{\mathrm{DCM}\left(25^{\circ} \mathrm{C}\right)}=1.33 \mathrm{~g} / \mathrm{mL}\right)$, air $\left(\rho_{\operatorname{air}\left(25^{\circ} \mathrm{C}-1013.25 \mathrm{mbar}\right)}=1.184 \mathrm{~kg} / \mathrm{m}^{3}\right)$, and nitrogen $\left(\rho_{\mathrm{N} 2}\left(25^{\circ} \mathrm{C}-1013.25 \mathrm{mbar}\right)\right.$ 
$=1.145 \mathrm{~kg} / \mathrm{m}^{3}$ ) were used to convert the volumetric flow rate of feed solution and atomizing airflow ( $\mathrm{mL} / \mathrm{min}$ and $\mathrm{L} / \mathrm{min}$, respectively) into mass flow rate $(\mathrm{g} / \mathrm{min}$ ). This dimensionless parameter allows correlating the atomization conditions to the droplet size and comparing the process atomization characteristics of spray-drying operating at different scales $[23,24]$.

- The ratio of the equipment volume to the minimum amount of API used when processing was calculated at both scales, respectively. Such a calculation allows estimation of the material loss on the glass wall's drying chamber for different manufacturing processes. The volume of the equipment was approximated by considering the geometry of the drying chamber equivalent to a cylinder.

Residence Time

The residence time of spray-dried particles in the miniaturized system and the Büchi B290 mini spray-dryer was roughly estimated as seen in Equation (1):

$$
t_{r}=\frac{V_{c}}{Q_{D A}}
$$

where $t_{r}$ is the droplets' residence time, $V_{c}$ is the volume of the drying chamber, and $Q_{D A}$ is the volumetric drying gas airflow. The main assumption is that the droplets' residence time approximates the air residence time in the chamber. Calculation of a volume cylinder was used to estimate the volume of the drying chamber.

\subsubsection{Powder Characterization}

\section{Modulated Differential Scanning Calorimetry}

Modulated differential scanning calorimetry (mDSC) analyses were conducted using TA Instruments Q1000 calorimeter (TA Instruments, Leatherhead, UK). About 2-4 mg of powder was analyzed in closed standard aluminium pans (TA Instruments, Leatherhead, UK). Samples were heated from -50 to $210{ }^{\circ} \mathrm{C}$ at $2{ }^{\circ} \mathrm{C} / \mathrm{min}$ combined with a modulation of $\pm 1{ }^{\circ} \mathrm{C}$ and a period of $40 \mathrm{~s}$. The thermograms were collected and data were processed using Universal Analysis 2000 software (TA Instruments, Leatherhead, UK). Glass transition temperature $\left(T_{g}\right)$ was evaluated in the reverse heat flow signal, while melting and crystallization events were both examined in the total and nonreverse heat flow signals.

\section{Thermogravimetric Analysis}

Thermogravimetric analysis (TGA) experiments were conducted on a TGA Q500 (TA Instruments, Leatherhead, UK). Spray-dried powder was heated from 25 to $300{ }^{\circ} \mathrm{C}$ at a constant heating rate of $2{ }^{\circ} \mathrm{C} / \mathrm{min}$. The chamber was swept by a $100 \mathrm{~mL} / \mathrm{min}$ flow rate of dry nitrogen. Data were processed using Universal Analysis 2000 software (TA Instruments, Leatherhead, UK).

\section{X-Ray Powder Diffraction}

X-ray powder diffraction (XRPD) experiments were performed on an X Bruker AXS D8 Advance (Bruker, Karlsruhe, Germany). Each sample was dropped on the center of a silicium monocrystal holder and analyzed at a scan speed of $2.5 \mathrm{~s} / \mathrm{step}$ and a step size of $0.02^{\circ}$ between $4.5^{\circ}$ and $30^{\circ}$. The diffractograms representing the intensity as a function of $2 \theta$ were processed using Eva DIFFRAC-SUITE software (Bruker, Karlsruhe, Germany).

\section{Scanning Electron Microscopy}

Scanning electron microscopy (SEM) observations were performed using the JEOL JSM-IT300 SEM (JEOL, Tokyo, Japan) to characterize the morphology of the spray-dried particles. An aluminium stud 
with a conductive double-sided carbon adhesive tape was used for sample preparation. Observations were made at an accelerating voltage of $5 \mathrm{kV}$ in high-vacuum mode. The data treatment and picture collection was realized using JEOL IT300 Operation software (JEOL, Tokyo, Japan).

\section{Results and Discussion}

\subsection{Operational Equipment Parameters and Its Comparison to Laboratory-Scale Büchi B290 Mini Spray-Dryer}

Prior to the development of the miniaturized screening device, design criteria and user requirements specifications were established to design a system that mimics the operating mode of a spray-dryer and that allows the adjustment of process and formulation variables in the range of values typically found at laboratory/pilot scale. A later stage comparison with large-scale (e.g., pilot/industrial) equipment would be undertaken to finalize the equipment evaluation. Table 1 provides a comparison of the operating modes and process conditions between the miniaturized device and the laboratory-scale Büchi B290 mini spray-dryer in terms of feed solution properties, equipment configuration, drying gas, and atomization process conditions.

Firstly, critical material attributes (CMAs), including solvent choice, concentration, DL, and selected carriers, were maintained during downscaling. It was demonstrated that the miniaturized spray-dryer can operate with feed solutions having different properties in terms of viscosity and surface tension and can produce amorphous material with different $T_{g}$ values. Secondly the miniaturized system allows the reproduction of critical process parameters (CPPs), e.g., inlet temperature, atomizing gas airflow, and feed flow rate, in the range of those of a laboratory-scale dryer, as detailed in Table 1. A bifluid nozzle was selected in the design of the novel equipment to be representative of droplet formation that occurs at laboratory scale. In this regard, atomizing-airflow-to-liquid-feed-flow-rate ratio was calculated using both our miniaturized device and laboratory-scale Büchi B290 mini spray-dryer. Values of 1.9 and 8.0 were obtained at laboratory and screening scales, respectively. The impact of applied atomization conditions will be further discussed in the equipment qualification section. According to Kemp et al. (2013), if the atomizing-gas-to-liquid ratio exceeds 6, a particle size of 2-3 $\mu \mathrm{m}$ can be generated [25]. However, this dimensionless parameter does not include the nozzle geometry/diameter, gas velocity, and feed solution concentration that also impacts the particle size distribution (PSD) in addition [23]. Herein, air was used as a drying and atomizing gas while nitrogen was generally applied at laboratory scale. Even if the atomizing-gas-to-liquid ratio was not kept constant during downscaling, the use of dimensionless parameters during scale-up/transfer procedure offered a first estimate of mechanisms occurring across spray-drying at various scales.

As detailed in Table 1, drying gas airflow was significantly reduced from 580 to $20 \mathrm{~L} / \mathrm{min}$ during downscaling. The smaller dimension of the drying chamber at miniaturized scale $(15 \times 2 \mathrm{~cm})$ compared to laboratory dryer $(47 \times 15.9 \mathrm{~cm})$ required a reduced drying gas airflow in order to avoid turbulence within the chamber. Additionally, the miniaturized dimension of the drying chamber was found to reduce droplets' residence time: values estimated at around 0.14 and $0.96 \mathrm{~s}$, respectively, were obtained for the miniaturized equipment and the Büchi B290 mini spray-dryer. This calculation considers a laminar drying airflow within the chamber which probably deviates to some extent to experimental conditions. Alternatively, computational fluid dynamics (CFD) simulations have been used to model the fluid dynamics inside Büchi B290 mini spray-dryer and allowed the estimation of the resident time under different process conditions [26]. The obtained values confirmed the smaller residence time of droplets within the chamber at the miniaturized scale, which limited its drying capacity compared to the larger dryer. In this way, the droplets need to be small enough to ensure they are completely dry before leaving the system. Based on these considerations, a smaller nozzle diameter $(0.15 \mathrm{~mm})$ and an increased atomizing airflow $(18 \mathrm{~L} / \mathrm{min})$ were chosen to generate smaller droplets from the nozzle and to ensure efficient droplet drying at miniaturized scale [27]. Additional experimental trials revealed that the miniaturized process is appropriate only for organic solvents as it was not able to operate with aqueous feed solution to ensure the complete drying of the droplets within the chamber. 
Table 1. Comparison of equipment operational parameters, equipment design, and performance between miniaturized atomization device and laboratory-scale Büchi B290 mini spray-dryer.

\begin{tabular}{|c|c|c|}
\hline & Miniaturized Atomization Device & Büchi B290 Mini Spray-Dryer \\
\hline \multicolumn{3}{|c|}{ Feed solution } \\
\hline Solvent & $\mathrm{DCM} / \mathrm{EtOH} 2: 1(v / v)$ & $\mathrm{DCM} / \mathrm{EtOH} 2: 1(v / v)$ \\
\hline Concentration of solutes & $5 \%(w / v)$ & $5 \%(w / v)$ \\
\hline DL & $20 \%-80 \%(w / w)$ & $20 \%-80 \%(w / w)$ \\
\hline Volume of feed solution & $0.25-1 \mathrm{~mL}$ & $100 \mathrm{~mL}$ \\
\hline Feed flow rate & $2 \mathrm{~mL} / \mathrm{min}$ & $4 \mathrm{~mL} / \mathrm{min}$ \\
\hline \multicolumn{3}{|c|}{ Equipment configuration } \\
\hline Drying chamber dimension (length $\times$ diameter) & $15 \times 2 \mathrm{~cm}$ & $47 \times 15.9 \mathrm{~cm}^{\mathrm{a}}$ \\
\hline Drying chamber surface area & $94.2 \mathrm{~cm}^{2 \mathrm{~b}}$ & $2.3 .10^{3} \mathrm{~cm}^{2 \mathrm{~b}}$ \\
\hline Drying chamber volume & $5.0 .10^{-2} \mathrm{~L}^{\mathrm{b}}$ & $9.3 \mathrm{~L}^{\mathrm{b}}$ \\
\hline Recycling loop configuration & open & closed \\
\hline \multicolumn{3}{|c|}{ Drying gas } \\
\hline Drying gas flow rate & $20 \mathrm{~L} / \mathrm{min}$ & $580 \mathrm{~L} / \mathrm{min}$ \\
\hline Drying gas & Air & $\mathrm{N}_{2}$ \\
\hline Heating power & $500 \mathrm{~W}$ & $2300 \mathrm{~W}^{\mathrm{a}}$ \\
\hline Inlet temperature & $100^{\circ} \mathrm{C}$ & $65^{\circ} \mathrm{C}$ \\
\hline Residence time & $0.14 \mathrm{~s}^{\mathrm{c}}$ & $0.96 \mathrm{~s}^{\mathrm{c}}$ \\
\hline \multicolumn{3}{|c|}{ Atomization } \\
\hline Nozzle selection & bifluid & bifluid \\
\hline Nozzle diameter & $0.15 \mathrm{~mm}$ & $0.7 \mathrm{~mm}$ \\
\hline Atomization gas flow rate & $18 \mathrm{~L} / \mathrm{min}$ & $9 \mathrm{~L} / \mathrm{min}$ \\
\hline Atomization gas & Air & $\mathrm{N}_{2}$ \\
\hline Atomization gas flow rate/Feed flow rate & $8.0^{\mathrm{c}}$ & $1.9^{\mathrm{c}}$ \\
\hline \multicolumn{3}{|c|}{ Particle separation system and powder properties } \\
\hline Particle separation principle & DSC pan & cyclone \\
\hline Particle separation selectivity & - & $2 \mu \mathrm{m}^{\mathrm{a}}$ \\
\hline Typical PSD obtained & $\leq 10 \mu \mathrm{m}^{\mathrm{d}}$ & $\leq 10 \mu \mathrm{m}^{\mathrm{d}}$ \\
\hline \multicolumn{3}{|c|}{ Equipment performance and output parameters } \\
\hline Minimum sample volume per batch & $0.25 \mathrm{~mL}$ & $30 \mathrm{~mL}^{\mathrm{a}}$ \\
\hline Corresponding minimum materials needs per batch & $12.5 \mathrm{mg} \mathrm{e}$ & $1.5 \mathrm{ge}^{\mathrm{e}}$ \\
\hline Production rate per hour & $4^{\mathrm{f}}$ & $1_{\mathrm{f}}^{\mathrm{f}}$ \\
\hline Typical yield value & $15 \%-50 \%$ & $65 \%-90 \%$ \\
\hline Outlet temperature & $40 \pm 5^{\circ} \mathrm{C}$ & $45 \pm 2{ }^{\circ} \mathrm{C}$ \\
\hline Drying chamber surface area $/ \mathrm{min}$. API used & $7.5 \times 10^{3} \mathrm{~cm}^{2} / \mathrm{g}$ b,e & $1.5 \times 10^{3} \mathrm{~cm}^{2} / \mathrm{g}, \mathrm{e}$ \\
\hline
\end{tabular}

a data obtained from literature and technical features of the Büchi B290 mini spray-dryer [28,29], ${ }^{\mathrm{b}}$ calculation of the lateral surface and the volume of a cylinder were used to estimate the surface area and the volume of the drying chamber, respectively, ${ }^{\mathrm{C}}$ calculation detailed in Methods section, ${ }^{\mathrm{d}}$ data experimentally obtained from SEM observations, ${ }^{\mathrm{e}}$ estimation based on minimum sample volume per batch and feed solution concentration used, ${ }^{\mathrm{f}}$ including thermal equilibration within the drying chamber, production, and cleaning of the system. 


\subsection{Equipment Performance and Comparison to a Büchi B290 Mini Spray-Dryer}

\subsubsection{API Consumption, Production Rate, and Yield Obtained}

As seen in Table 1, the main benefit of using the miniaturized equipment relies on its capability to significantly reduce the API amount needed for a production. The use of this novel equipment would lead to an API saving by a factor of 120. Additionally, a production rate of four samples per hour, including thermal equilibration within the drying chamber, production, and cleaning of the system, can be achieved with the proposed device, i.e., production rates are improved fourfold compared to the laboratory dryer. These two elements confirm the great potential of our miniaturized device to address formulation development constraints during screening phases when API is scarce and time for development is very limited.

Equipment performance, including yield evaluation of the spray-dried material, was performed at both scales. As detailed in Table 1, yield values of up to 50\% can be obtained when using our miniaturized equipment at the milligram scale, while typical yield values obtained at laboratory scale, i.e., for gram-scale productions, range from $65 \%$ to $90 \%$. The lower yield obtained at the miniaturized scale compared to the laboratory spray-dryer can be explained by the batch size differences produced at both scales. It is well known that the production of extremely small batch sizes at the milligram scale leads to a drop in the yield of the spray-dried material [18]. Additionally, the yield variation found between both manufacturing processes can be also attributed to the higher equipment surface area in relation to the used material at the miniaturized scale $\left(7.5 \times 10^{3} \mathrm{~cm}^{2} / \mathrm{g}\right)$ compared to the laboratory dryer $\left(1.5 \times 10^{3} \mathrm{~cm}^{2} / \mathrm{g}\right)$. This represents almost a fivefold increase of such parameters at a smaller scale that translates to an increased risk of having spray-dried material deposit on the wall of the drying chamber during the process.

Despite a lower yield value at the miniaturized scale, sufficient spray-dried material was collected for subsequent analytical characterization. Contrary to laboratory-scale equipment, where powder separation occurs across a cyclone [30], experimental trials revealed that the finetuned system of powder collection into a DSC pan described in the Methods section allowed for the maximization of the collection of fine particles generated at the miniaturized scale. This design was found to be particularly suitable to remove powder handling after processing, facilitate the powder preparation, and transfer to later analytical characterization. This setup is advantageous in terms of operating, cleaning, throughput, and cross-contamination.

\subsubsection{Outlet Temperature Monitoring}

Measurements of outlet temperature $\left(\mathrm{T}_{\text {out }}\right)$ at the bottom of the drying chamber confirmed the ability of the novel device to reproduce $\mathrm{T}_{\text {out }}$ in the range of values typically used at laboratory scale. Values of $40 \pm 5{ }^{\circ} \mathrm{C}$ and $45 \pm 2{ }^{\circ} \mathrm{C}$ were measured at screening and laboratory scales, respectively. Despite the fact that our miniaturized equipment operates at a higher inlet temperature $\left(100{ }^{\circ} \mathrm{C}\right)$ compared to laboratory equipment $\left(65^{\circ} \mathrm{C}\right)$, similar $\mathrm{T}_{\text {out }}$ values were obtained. This can be explained by the differences in terms of recycling loop configuration and heat loss among the two processes [31,32]. On the latter point, the smaller dimension of the miniaturized drying chamber is expected to reduce the heat loss through the glass wall of the chamber compared to laboratory- or pilot-scale dryers. This last point is confirmed by the calculation of the drying chamber surface area of both investigated processes, as detailed in Table 1 . Surface areas of $94.2 \mathrm{~cm}^{2}$ and $2.3 \times 10^{3} \mathrm{~cm}^{2}$ were estimated at the miniaturized and laboratory scale, respectively.

$\mathrm{T}_{\text {out }}$ is often considered as one of the most important CPPs of spray-drying, identified as a key process parameter to be evaluated during the scale-up procedure $[28,33,34]$. As $\mathrm{T}_{\text {out }}$ represents the highest temperature encountered by the dried particles during droplet drying [19], a change in $T_{\text {out }}$ can affect the physical and structural properties of the particles. In this regard, the fact that similar $\mathrm{T}_{\text {out }}$ values were maintained during downscaling ensures a reproducible production process and therefore 
provides consistent product quality. The impact of $\mathrm{T}_{\text {out }}$ used at both scales will be further discussed in the equipment qualification section.

Herein, the relatively low $\mathrm{T}_{\text {out }}$ value (approximately $45^{\circ} \mathrm{C}$ ) would allow the production of a large set of ASDs, including low $T_{g}$ samples, by reducing the risk of stickiness of the spray-dried amorphous material to the glass wall [35]. It is important that the development of robust process conditions of spray-drying takes into account the drying efficiency to reduce the level of residual solvent and to prevent phase separation while maximizing powder collection [36,37]. As a result, the value of $T_{\text {out }}$ is often a compromise between these factors [38].

\subsection{Equipment Qualification: Comparison of Particle/Powder Attributes of SDSDs Generated from the Two Scale Manufacturing Processes}

\subsubsection{Particles' Morphology}

The proposed miniaturized equipment was qualified by producing binary SDSDs of itraconazole at the milligram scale and comparing the powder/particle properties with respective samples produced by the laboratory dryer. Characterization of the structural shape of spray-dried particles is of particular interest as it provides evidence on how solvent evaporation and particles' formation occur during the drying process [39]. Since SDSD is a formulation intermediate that needs to be further processed prior to preclinical or clinical application, powder properties such as bulk density and flowability are critical quality attributes. These powder attributes are often a linked to the structural and morphological characteristics of spray-dried particles. In this regard, the morphology of itraconazole 40:60 (w/w) SDSD particles produced using the novel screening device and the laboratory-scale Büchi B290 mini spray-dryer was examined by SEM, and images are provided in Figures 2 and 3, respectively.

a)

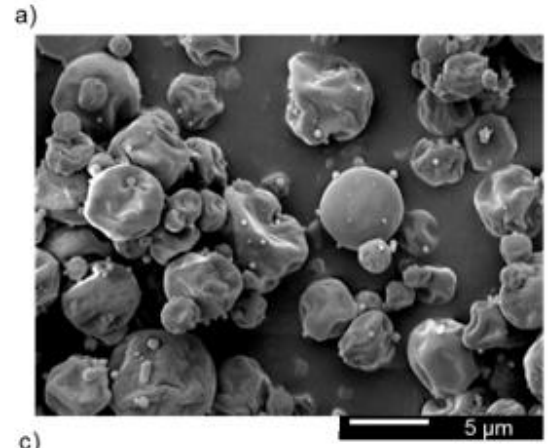

c)

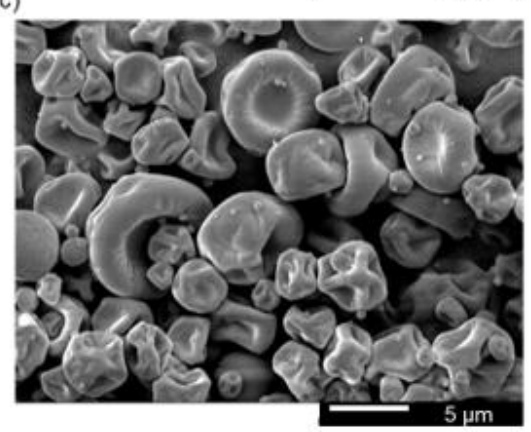

b)

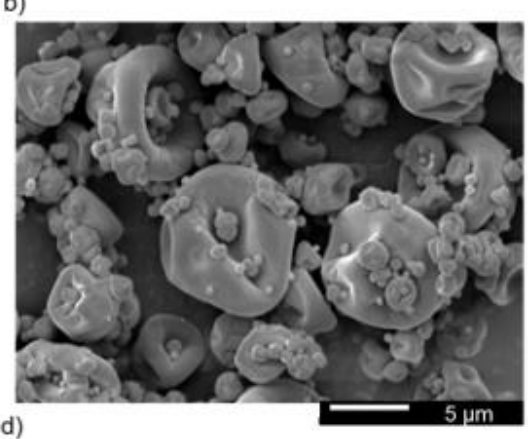

d)

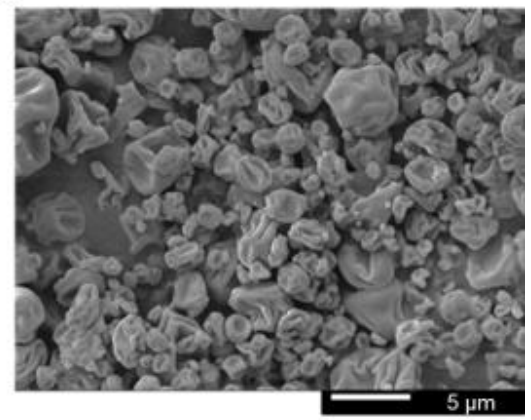

Figure 2. SEM microphotographs of 40:60 ( $w / w)$ itraconazole spray-dried solid dispersions (SDSDs) prepared using our miniaturized device with: PVPVA (a), PVPK30 (b), HPMCAS-LF (c), and Eudragit L100-55 (d).

As seen in Figure 2, the spray-dried particles of itraconazole ASDs prepared at a smaller scale display a spherical shape with a shriveled surface for all tested carriers. Additionally, the smallest particles of itraconazole/PVPVA and itraconazole/PVPK30 40:60 (w/w) SDSDs display a spherical 
shape with a smooth surface (Figure 2a,b). At laboratory scale, particles with similar morphology were obtained for the respective samples. As seen in Figure 3, spherical particles with a shriveled surface were found for SDSDs prepared with PVPVA, PVPK30, and HPMCAS-LF (Figure 3a-c), while spherical particles with a rough surface were found with Eudragit L100-55 SDSD (Figure 3d).

a)

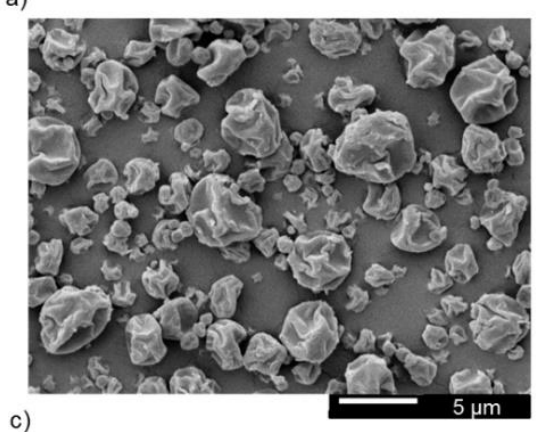

c)

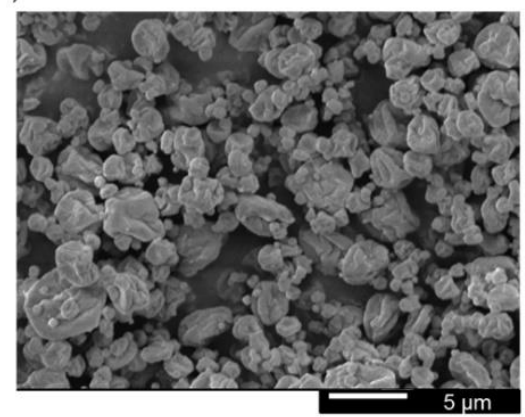

b)
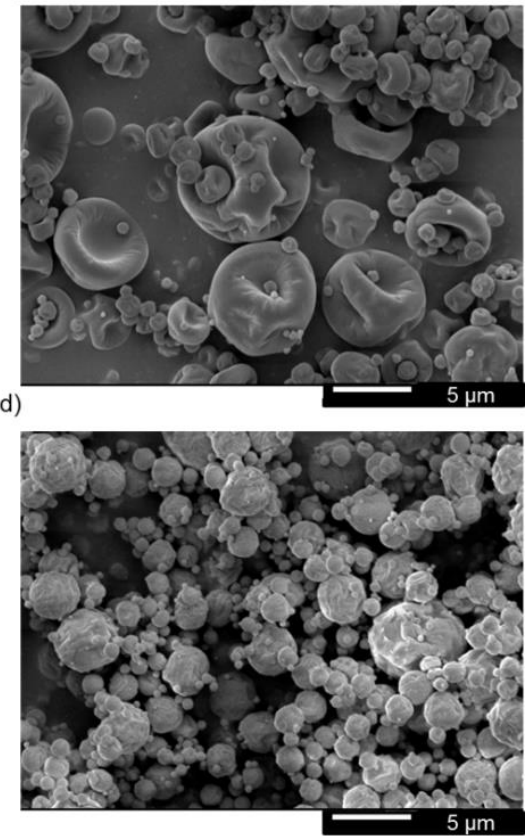

Figure 3. SEM microphotographs of 40:60 (w/w) itraconazole SDSDs prepared using Büchi B290 mini spray-dryer with: PVPVA (a), PVPK30 (b), HPMCAS-LF (c), and Eudragit L100-55 (d).

The fact that SDSDs produced at both screening and laboratory scales were found to have similarities in morphology can be attributed to a comparable $\mathrm{T}_{\text {out }}$ value and similar feed solution concentrations maintained during downscaling [6]. The morphological structure obtained, i.e., particles with a spherical shape and shriveled surface, is typical of the spray-drying of pharmaceutical material with a relatively low feed solution concentration and relatively low $\mathrm{T}_{\text {out }}$. As mentioned in previous sections, the feed solution concentration was fixed at $5 \%(w / v)$, while $\mathrm{T}_{\text {out }}$ was measured at around $45{ }^{\circ} \mathrm{C}$ with both equipment. As feed solution concentration influences the shell thickness formed in the early phase of droplet drying and $\mathrm{T}_{\text {out }}$ directly impacts the droplet drying time, the selected process conditions increase the time window for shell flexibility and favor the probability of obtaining shriveled particles [6]. In this regard, several studies have highlighted the influence of $\mathrm{T}_{\text {out }}$ on the particle morphology of spray-dried material in various industrial sectors [40], and powder properties such as density, morphology, and mechanical strength are directly impacted by the $\mathrm{T}_{\text {out }}$ value [41]. Additionally, the fact that itraconazole/Eudragit L100-55 of 40:60 (w/w) solid dispersion display particles with different morphological properties than other SDSDs generated at laboratory scale can be attributed to the influence of the carrier used in the blend. This is linked to the fact that mechanical properties and flexibility of the shell formed early during droplet drying varies according to the polymer type [6,42].

SEM analysis was also used to provide information regarding the PSD of SDSDs produced at both scales. As seen in Figures 2 and 3, fine particles with a PSD lower than $10 \mu \mathrm{m}$ was generated using both our miniaturized equipment and Büchi B290 mini spray-dryer. This observation is typical for spray-dried particles generated from a bifluid nozzle, where atomization of the solution is obtained by the pressure of a compressed carrier gas and generally conducts to the formation of relatively low 
particle sizes [43]. This finding qualifies the choice made in the design of this miniaturized equipment regarding atomization conditions, especially.

Additional observations in SEM revealed that a fraction of particles generated at a small scale was found lower than $2 \mu \mathrm{m}$ (Figure 2a-c), which is below the cyclone efficiency of the laboratory-scale dryer. In contrast, the proposed design for the screening atomization device does not include a cyclone to collect the dried particles from the exhaust airflow. As detailed in the Methods section, the spray-dried material, including the smallest particles (typically in the nanometer size range), is directly sent into a DSC pan, while for laboratory dryer, these particles are typically carried out of the cyclone by the air stream. Moreover, the presence of very fine particles collected can be also explained on the basis that a smaller nozzle diameter $(0.15 \mathrm{~mm})$ and higher atomizing gas airflow $(18 \mathrm{~L} / \mathrm{min})$ have been used at small scale to ensure efficient drying of the droplets within the chamber. This observation translates well with the atomizing-airflow-to-liquid-flow-rate ratio calculation summarized in the previous section, where particle sizes as small as $2-3 \mu \mathrm{m}$ were expected at the screening scale.

\subsubsection{Miscibility and Solid State Properties of SDSDs}

First, the solid state of solid dispersions generated at both screening and laboratory scales was examined using XRPD. Results obtained for 40:60 and 60:40 $(w / w)$ SDSDs are depicted in Figure 4. All samples produced using our miniaturized equipment were characterized by the presence of an amorphous halo and the absence of Bragg peaks in XRPD pattern. Similar results were obtained for the respective reference samples produced with a larger spray-dryer. The fact that all solid dispersions produced at both scales were characterized as amorphous solids suggests that the selected process conditions prevent drug recrystallization during the manufacturing process. This finding reinforces the ability of our miniaturized equipment to manufacture amorphous SDSDs, correlating well with respective samples produced with the larger dryer.
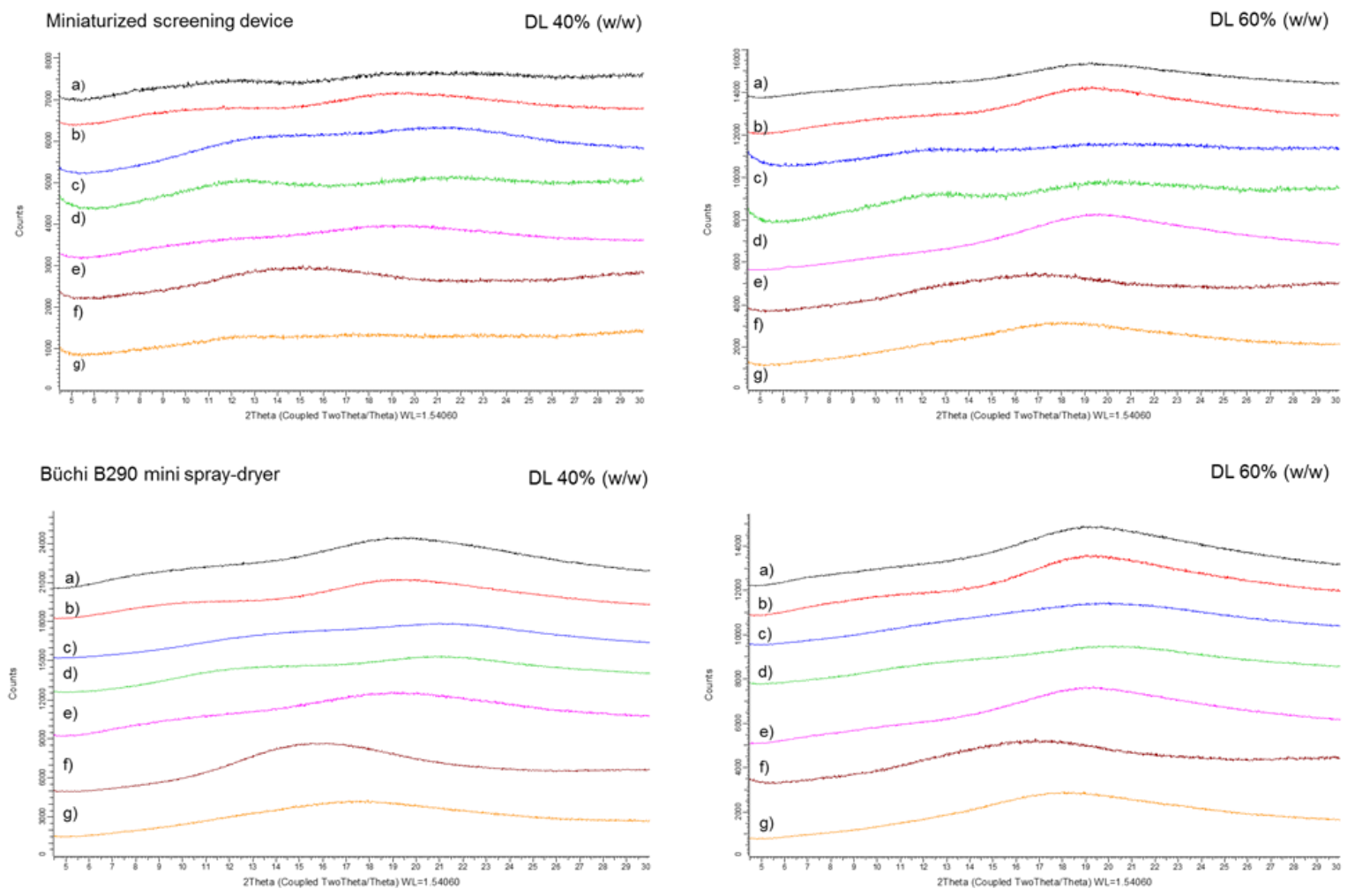

Figure 4. XRPD patterns of 40:60 and 60:40 (w/w) SDSDs of itraconazole with HPMCP HP50 (a), HPMCAS-LF (b), PVPVA (c), PVPK30 (d), Soluplus (e), Eudragit L100 (f), and Eudragit L100-55 (g) produced by the miniaturized screening device and Büchi B290 mini spray-dryer. 
Additionally, the drug-polymer miscibility of itraconazole ASDs was characterized using mDSC. Figure 5 displays the mDSC thermograms obtained for 40:60 (w/w) itraconazole SDSDs produced at both screening and laboratory scales. Glass solutions, depicted by the presence of a single $T_{g}$ in the reverse heat flow signal of mDSC, were found for all 40:60 (w/w) ASDs produced from the two techniques.
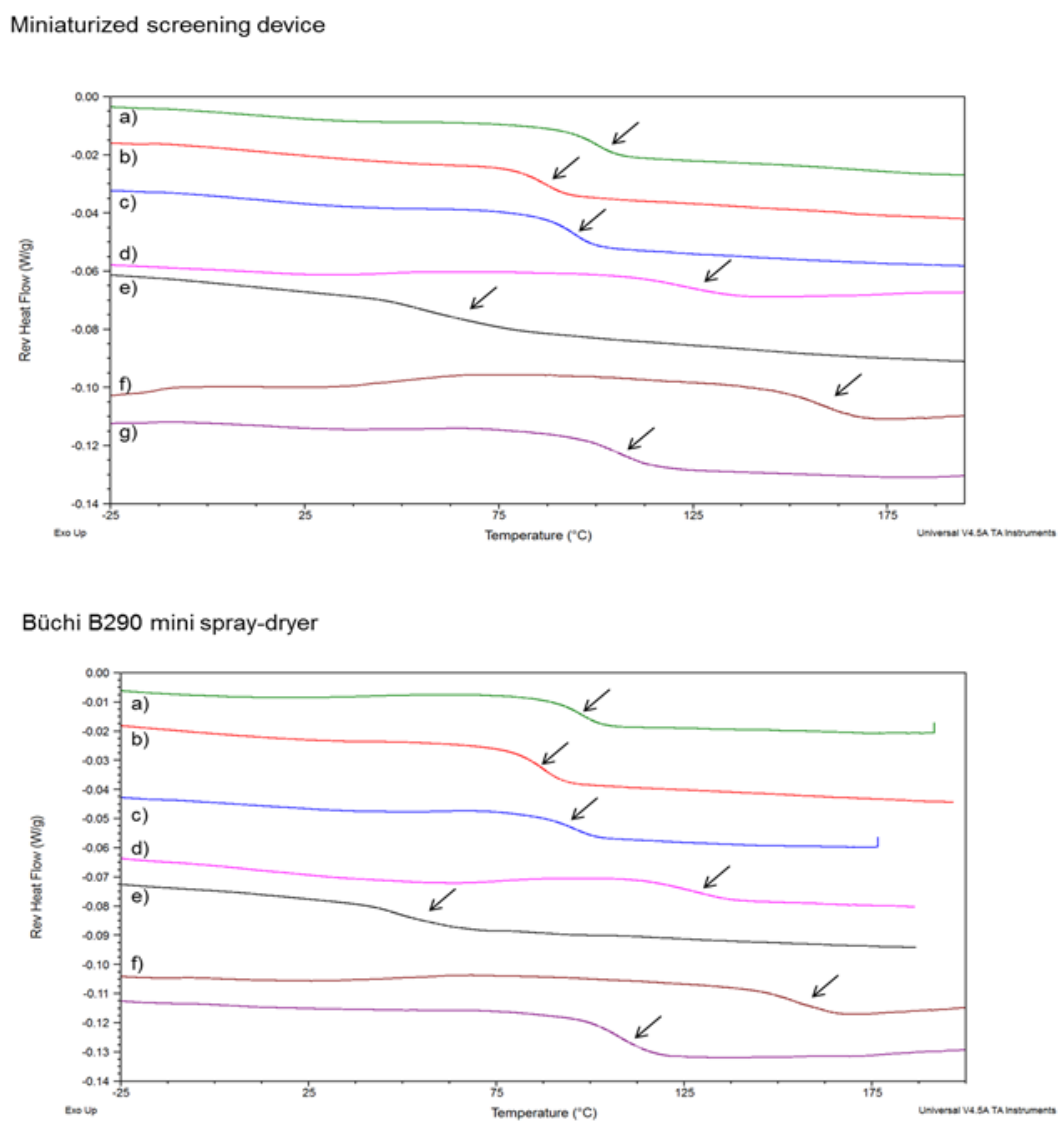

Figure 5. Reverse heat flow signals of 40:60 (w/w) SDSDs of itraconazole with HPMCP HP50 (a), HPMCAS-LF (b), PVPVA (c), PVPK30 (d), Soluplus (e), Eudragit L100 (f), and Eudragit L100-55 (g) produced by the miniaturized screening device and Büchi B290 mini spray-dryer.

The mean $T_{g}$ values of obtained glass solutions are summarized in Table 2. Similar $T_{g}$ values were obtained for all tested drug-polymer combinations. Assessment of $T_{g}$ properties during ASD screening is known to provide useful information regarding the physical stability of amorphous system [44]. Again, this confirms the robustness of our miniaturized equipment to gain insight into final properties of SDSDs.

Table 2. Summary of $T_{g}$ values and percentage of weight loss of 40:60 (w/w) binary amorphous solid dispersions (ASDs) of itraconazole generated at both screening and laboratory scales.

\begin{tabular}{ccccc}
\hline \multirow{2}{*}{$40: 60(w / w)$ ASDs } & \multicolumn{2}{c}{ Miniaturized Atomization Device } & \multicolumn{2}{c}{ Büchi B290 Mini Spray-Dryer } \\
\cline { 2 - 5 } & $\boldsymbol{T}_{\boldsymbol{g}}{ }^{\mathbf{a}}\left({ }^{\circ} \mathbf{C}\right)$ & \% Weight Loss $^{\mathbf{b}}$ & $\left.\boldsymbol{T}_{\boldsymbol{g}}{ }^{\mathbf{a}}{ }^{\circ} \mathbf{C}\right)$ & \% Weight Loss $^{\mathbf{b}}$ \\
\hline itraconazole/HPMCP HP50 & $100.5 \pm 0.1$ & 1.8 & $99.7 \pm 0.9$ & 1.8 \\
itraconazole/HPMCAS-LF & $85.4 \pm 1.8$ & 1.7 & $87.4 \pm 0.6$ & 1.2 \\
itraconazole/PVPVA & $94.2 \pm 0.3$ & 4.3 & $95.9 \pm 0.3$ & 4.0 \\
\hline
\end{tabular}


Table 2. Cont.

\begin{tabular}{ccccc}
\hline \multirow{2}{*}{$40: 60(w / w)$ ASDs } & \multicolumn{2}{c}{ Miniaturized Atomization Device } & \multicolumn{2}{c}{ Büchi B290 Mini Spray-Dryer } \\
\cline { 2 - 5 } & $\boldsymbol{T}_{\boldsymbol{g}}{ }^{\mathbf{a}}\left({ }^{\circ} \mathbf{C}\right)$ & \% Weight Loss $^{\mathbf{b}}$ & $\boldsymbol{T}_{\boldsymbol{g}}{ }^{\mathbf{a}}\left({ }^{\circ} \mathbf{C}\right)$ & \% Weight Loss $^{\mathbf{b}}$ \\
\hline itraconazole/PVPK30 & $128.6 \pm 0.7$ & 9.0 & $128.7 \pm 1.0$ & 8.6 \\
itraconazole/Soluplus & $53.9 \pm 1.6$ & 2.8 & $50.2 \pm 1.6$ & 2.3 \\
itraconazole/Eudragit L100 & $158.8 \pm 2.1$ & 3.4 & $160.2 \pm 1.5$ & 3.6 \\
itraconazole/Eudragit L100-55 & $107.3 \pm 1.5$ & 1.9 & $106.7 \pm 0.4$ & 1.5 \\
\hline
\end{tabular}

${ }^{\mathrm{a}}$ mean $\mathrm{Tg}$ value obtained from triplicate measurements performed in $\mathrm{mDSC},{ }^{\mathrm{b}}$ obtained from TGA analysis.

Similarly, the phase behavior of 60:40 $(w / w)$ itraconazole solid dispersions prepared at the screening scale was compared to respective samples prepared at the laboratory scale with Büchi B290 mini spray-dryer, as detailed in Figure 6. Regarding both techniques, glass solutions were obtained with HPMCP HP50, HPMCAS-LF, Eudragit L100, and Eudragit L100-55, exclusively. The thermograms of samples made with PVPVA, PVPK30, and Soluplus displayed the presence of drug melting in reverse heat flow signal. More precisely, the drug recrystallization process was identified in the total heat flow signal (data not shown) and can be interpreted as a sign of ASD instability. Moreover, phase separation was observed by the presence of multiple $T_{g}$ values in the reverse heat flow signals of PVPVA and PVPK30 ASDs. In the case of itraconazole/PVPK30 60:40 (w/w), the $T_{g}$ of pure glassy itraconazole, its inherent mesophase endotherms, and a second $T_{g}$ linked to a polymer rich domain were identified [45]. ASDs identified as an amorphous phase separated system are not the preferred choice, as these systems are more prone to recrystallization during storage than ideal glass solutions [46].

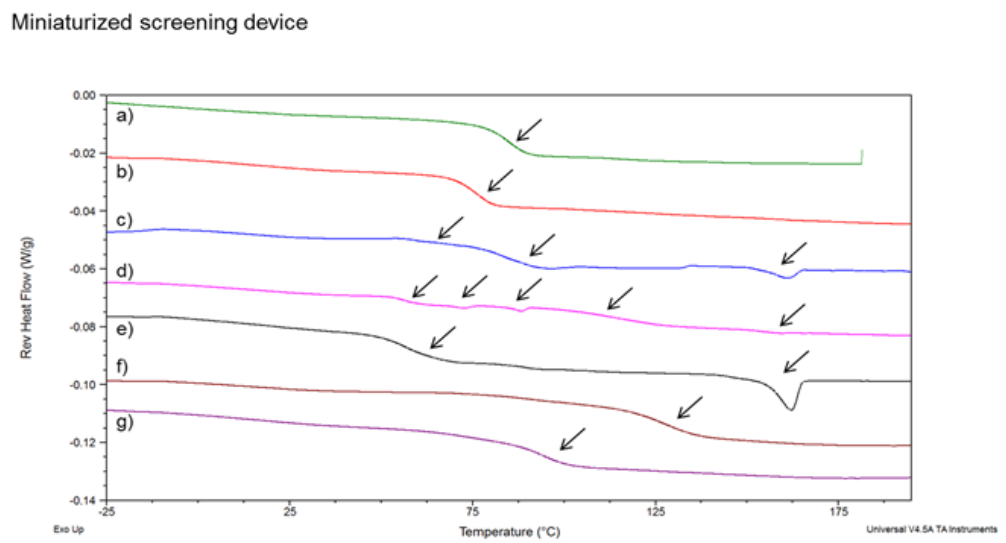

Büchi B290 mini spray-dryer

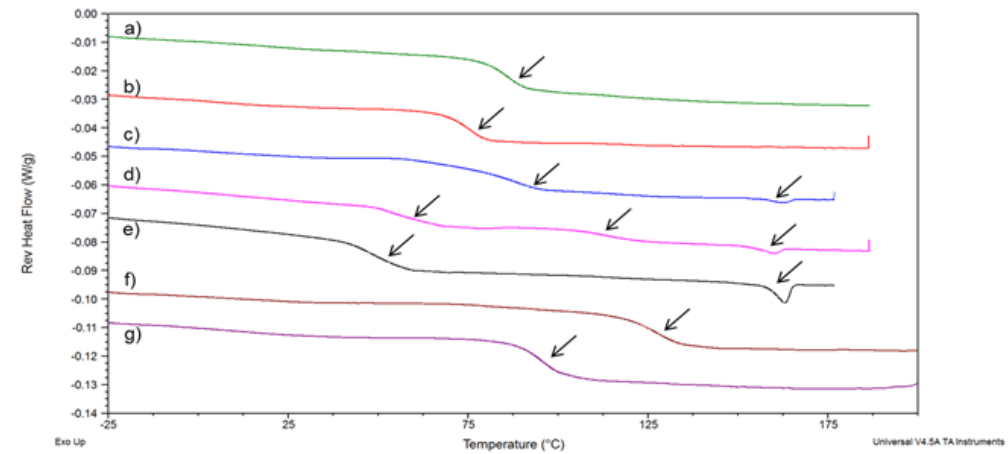

Figure 6. Reverse heat flow signals of 60:40 (w/w) SDSDs of itraconazole with HPMCP HP50 (a), HPMCAS-LF (b), PVPVA (c), PVPK30 (d), Soluplus (e), Eudragit L100 (f), and Eudragit L100-55 (g) produced by the miniaturized screening device and Büchi B290 mini spray-dryer. 
Table 3 summarizes the phase behavior of itraconazole SDSDs at various DLs using both manufacturing processes. Results obtained with the novel atomization device suggest its robustness to consistently reproduce the phase behavior of itraconazole SDSDs produced at laboratory scale. Because the inherent miscibility of SDSD is a direct consequence of droplets drying kinetically during the spray-drying process, this finding confirms the ability of our novel miniaturized equipment to reproduce the microscale evaporation mechanism that occurs across a larger dryer. During droplet solvent evaporation, a drug may have the opportunity to recrystallize during a small interval of time when drug solubility reaches saturation in a solvent and when polymer viscosity is not enough to stabilize the amorphous form of the drug [8]. Therefore, this qualifies the design and operating mode of our miniaturized system compared to laboratory equipment. At this stage, additional tests to investigate the physical stability and dissolution performance of the most promising itraconazole-polymer combinations (e.g., made with Eudragit L100, HPMCP HP50, HPMCAS-LF, and Eudragit L100-55) would enable the finetuning of the carrier selection.

Interestingly, the miscibility of itraconazole/Eudragit L100 produced at the screening scale was improved up to $80 \%(w / w)$ DL compared to the respective ASD produced at the laboratory scale of up to $60 \%(w / w)$ DL (Table 3). Although $\mathrm{T}_{\text {out }}$ was kept constant during the downscale approach, this cannot predict the entire impact on powder properties regarding the changes in other CPPs like drying and atomizing gas flow rate or inlet temperature [21,37]. As mentioned in the previous sections, changes in process conditions and equipment design of the miniaturized system have been made during downscaling, e.g., selection of atomization conditions and inlet temperature adapted to the smaller drying chamber or the use of an appropriate powder collection system for small SDSD batches. This has resulted in the collection of a fraction of spray-dried particles below the cyclone efficiency of laboratory dryer (Figure 2), which may explain the improved miscibility obtained for screened ASD. Due to the fact that smaller droplets are known to undergo a faster evaporation rate compared to larger droplets, the window for phase separation is minimized and therefore a higher level of drug-polymer mixing can be achieved [47]. Thus, the miscibility difference found for itraconazole/Eudragit L100 80-20 (w/w) produced at laboratory and screening scales is probably the result of the combined effects of smaller droplet sizes generated from the nozzle, different drying kinetics/residence time within the chamber, and improved selectivity of powder collection system.

\subsubsection{Moisture and Residual Solvent Content of SDSDs}

Finally, TGA analyses were performed on 40:60 $(w / w)$ itraconazole ASDs and percentages of weight loss recorded during experiments are summarized in Table 2. TGA experiments allow for the rough estimation of the percentage of residual solvent and moisture content in spray-dried material. Quantification of trace-level residual solvent can be performed using gas chromatography [36]. As seen in Table 2, similar percentage of mass loss values were found for samples generated from the two techniques. Solid dispersions that contain polymers such as PVPVA and PVPK30 display a higher percentage of weight loss recorded during the heating process compared to other carriers. This can be attributed to the inherent hygroscopicity of these carriers. More specifically, TGA results suggest that solid dispersions produced at both scales contain a similar amount of solvent and moisture content. This finding corroborates the similarities obtained regarding the phase behavior and thermal properties of SDSDs at screening and laboratory scales, as illustrated in Figures 5 and 6. Because residual solvent content acts as a plasticizing agent that disrupts drug-polymer interactions, decreases the $T_{g}$ value of amorphous system, and thus increases the molecular mobility, the physical and chemical stability of the drug will be negatively impacted $[48,49]$. In this context, the proposed miniaturized equipment offers an invaluable alternative to the standard screening approach, e.g., film casting, where the residual solvent content is the major drawback of this methodology. Indeed, film-casted samples have a generally relatively high solvent content that affects the performance of screened ASDs [50]. This can generate false-negative results among screened drug-polymer combinations and hence falsify the general outcome of the screening procedure [51]. 
Table 3. Reproducibility of the miniaturized device (Min) to predict the phase behavior of itraconazole solid dispersions produced at laboratory scale (Lab) with Büchi B290 at 20\%, 40\%,60\%, and 80\% $(w / w)$ DL. Green color used in the Table refers to the formation of glass solutions where amorphous drug is molecularly dispersed in the carrier, orange color refers to the presence of residual crystallinity in the ASD or drug recrystallization process recorded during mDSC analysis.

\begin{tabular}{|c|c|c|c|c|c|c|c|c|}
\hline ASDs & HРMCP HP50 & HPMCAS-LF & PVPVA & PVPK30 & Soluplus & Eudragit L100 & & Eudragit L100-55 \\
\hline DLScale & Lab & Lab & Min & Min & Min & Lab & Min & Min \\
\hline $\begin{array}{l}20: 40 \\
(w / w)\end{array}$ & \multirow{3}{*}{ Glass solution } & \multirow{3}{*}{ Glass solution } & \multirow[t]{3}{*}{ Glass solution } & \multirow[t]{3}{*}{ Glass solution } & \multirow[t]{2}{*}{ Glass solution } & & & \\
\hline $\begin{array}{l}40: 60 \\
(w / w)\end{array}$ & & & & & & & & \\
\hline $\begin{array}{c}60: 40 \\
(w / w)\end{array}$ & & & & & & Glass solution & & Glass solution \\
\hline $\begin{array}{c}80: 20 \\
(w / w)\end{array}$ & $\begin{array}{c}\text { Drug } \\
\text { melting/recryst. }\end{array}$ & $\begin{array}{c}\text { Drug } \\
\text { melting/recryst. }\end{array}$ & $\begin{array}{c}\text { Drug } \\
\text { melting/recryst. }\end{array}$ & $\begin{array}{c}\text { Drug } \\
\text { melting/recryst. }\end{array}$ & $\begin{array}{l}\text { Drug } \\
\text { melting/recryst. }\end{array}$ & $\begin{array}{c}\text { Drug } \\
\text { melt/recryst. }\end{array}$ & GS. & $\begin{array}{c}\text { Drug } \\
\text { melting/recryst. }\end{array}$ \\
\hline
\end{tabular}




\section{Conclusions}

Our miniaturized system was found to consistently reproduce the properties of SDSDs produced at the laboratory scale. Thus, the application of this novel device in pharmaceutical development laboratories would help to guide scientists in the rational selection of adequate polymer and DL selection for the development of SDSDs. This screening device would be invaluable in the early stages of development when API availability and time for experimental work are scarce. An API saving by a factor of 120 and a fourfold increased production rate per hour can be achieved with the proposed system. The miniaturized system has been specially designed to operate with low volumes of feed solution $(0.25-1 \mathrm{~mL})$ and was optimized for powder collection and ease of sample collection for subsequent analytical characterization. The fact that the critical quality attributes of itraconazole SDSDs widely translate to those manufactured at the laboratory scale in terms of morphology, PSD, drug-polymer miscibility/solid state, and moisture/residual solvent content, qualifies the design, operating mode, as well as the performance of our miniaturized screening device. This suggests the ability of this small-scale equipment to reproduce the evaporation and particle formation processes that occur at the laboratory scale. This is symbolized by the constant value of $\mathrm{T}_{\text {out }}$ throughout downscaling approach that would ease the transfer from screening phases to laboratory productions. Based on this positive correlation, future studies will focus on the investigation of reproducibility between the novel device and a large-scale spray-dryer ( $\mathrm{kg}$ scale) in terms of output parameters and particle/powder attributes. Additionally, further work could focus on the possibility of leveraging Process Analytical Technology (PAT) for the miniaturized screening device to measure droplets/particle characteristics and heat/mass transfer online.

Author Contributions: Conceptualization, A.O., J.M., and P.S.; Data curation, A.O.; Formal analysis, A.O., J.M., P.S., and K.D.; Funding acquisition, K.D.; Investigation, A.O.; Methodology, A.O. and K.D.; Project administration, F.R., M.A.S., and K.D.; Resources, F.R. and M.A.S.; Software, A.O.; Supervision, F.R., M.S., P.S., and K.D.; Validation, K.D.; Visualization, A.O.; Writing-original draft, A.O.; Writing-review \& editing, J.M., F.R., M.A.S., P.S., and K.D.

Funding: This work is part of the PhD research of Aymeric Ousset and it was funded by the Product Development department of UCB Pharma.

Acknowledgments: The authors would like to thank the grant from the Product Development department of UCB Pharma, the technical assistance from the solid state characterization group and the technical support from the laboratory and engineering services of UCB Pharma, with a particular attention to Jean-Claude Toussaint.

Conflicts of Interest: The authors declare no conflict of interest.

\section{References}

1. Singh, A.; Van den Mooter, G. Spray drying formulation of amorphous solid dispersions. Adv. Drug Deliv. Rev. 2016, 100, 27-50. [CrossRef] [PubMed]

2. Broadhead, J.; Edmond Rouan, S.K.; Rhodes, C.T. The spray drying of pharmaceuticals. Drug Dev. Ind. Pharm. 1992, 18, 1169-1206. [CrossRef]

3. Tontul, I.; Topuz, A. Spray-drying of fruit and vegetable juices: Effect of drying conditions on the product yield and physical properties. Trends Food Sci. Technol. 2017, 63, 91-102. [CrossRef]

4. Wisniewski, R. Spray drying technology review. In Proceedings of the 45th International Conference on Environmental Systems, Bellevue, WA, USA, 12-16 July 2015; pp. 1-46.

5. Maltesen, M.J.; Bjerregaard, S.; Hovgaard, L.; Havelund, S.; van de Weert, M. Quality by design-spray drying of insulin intended for inhalation. Eur. J. Pharm. Biopharm. 2008, 70, 828-838. [CrossRef] [PubMed]

6. Vicente, J.; Pinto, J.; Menezes, J.; Gaspar, F. Fundamental analysis of particle formation in spray drying. Powder Technol. 2013, 247, 1-7. [CrossRef]

7. Vasconcelos, T.; Marques, S.; das Neves, J.; Sarmento, B. Amorphous solid dispersions: Rational selection of a manufacturing process. Adv. Drug Deliv. Rev. 2016, 100, 85-101. [CrossRef] [PubMed]

8. Haser, A.; Cao, T.; Lubach, J.; Listro, T.; Acquarulo, L.; Zhang, F. Melt extrusion vs. Spray drying: The effect of processing methods on crystalline content of naproxen-povidone formulations. Eur. J. Pharm. Sci. 2017, 102, 115-125. [CrossRef] [PubMed] 
9. Vo, C.L.N.; Park, C.; Lee, B.J. Current trends and future perspectives of solid dispersions containing poorly water-soluble drugs. Eur. J. Pharm. Biopharm. 2013, 85, 799-813. [CrossRef] [PubMed]

10. Vasconcelos, T.; Sarmento, B.; Costa, P. Solid dispersions as strategy to improve oral bioavailability of poor water soluble drugs. Drug Discov. Today 2007, 12, 1068-1075. [CrossRef] [PubMed]

11. Vialpando, M.; Smulders, S.; Bone, S.; Jager, C.; Vodak, D.; Van Speybroeck, M.; Verheyen, L.; Backx, K.; Boeykens, P.; Brewster, M.E.; et al. Evaluation of three amorphous drug delivery technologies to improve the oral absorption of flubendazole. J. Pharm. Sci. 2016, 105, 2782-2793. [CrossRef] [PubMed]

12. Janssens, S.; De Zeure, A.; Paudel, A.; Van Humbeeck, J.; Rombaut, P.; Van den Mooter, G. Influence of preparation methods on solid state supersaturation of amorphous solid dispersions: A case study with itraconazole and eudragit e100. Pharm. Res. 2010, 27, 775-785. [CrossRef] [PubMed]

13. Janssens, S.; Van den Mooter, G. Review: Physical chemistry of solid dispersions. J. Pharm. Pharmacol. 2009, 61, 1571-1586. [CrossRef] [PubMed]

14. Chiang, P.C.; Ran, Y.; Chou, K.J.; Cui, Y.; Sambrone, A.; Chan, C.; Hart, R. Evaluation of drug load and polymer by using a 96-well plate vacuum dry system for amorphous solid dispersion drug delivery. AAPS PharmSciTech 2012, 13, 713-722. [CrossRef] [PubMed]

15. Konno, H.; Taylor, L.S. Influence of different polymers on the crystallization tendency of molecularly dispersed amorphous felodipine. J. Pharm. Sci. 2006, 95, 2692-2705. [CrossRef] [PubMed]

16. Ousset, A.; Chavez, P.F.; Meeus, J.; Robin, F.; Schubert, M.A.; Somville, P.; Dodou, K. Prediction of phase behavior of spray-dried amorphous solid dispersions: Assessment of thermodynamic models, standard screening methods and a novel atomization screening device with regard to prediction accuracy. Pharmaceutics 2018, 10, 1-29. [CrossRef] [PubMed]

17. Huang, S.; Williams, R.O. Effects of the preparation process on the properties of amorphous solid dispersions. AAPS PharmSciTech 2018, 19, 1971-1984. [CrossRef] [PubMed]

18. Ormes, J.D.; Zhang, D.; Chen, A.M.; Hou, S.; Krueger, D.; Nelson, T.; Templeton, A. Design of experiments utilization to map the processing capabilities of a micro-spray dryer: Particle design and throughput optimization in support of drug discovery. Pharm. Dev. Technol. 2013, 18, 121-129. [CrossRef] [PubMed]

19. Paudel, A.; Worku, Z.A.; Meeus, J.; Guns, S.; Van den Mooter, G. Manufacturing of solid dispersions of poorly water soluble drugs by spray drying: Formulation and process considerations. Int. J. Pharm. 2013, 453, 253-284. [CrossRef] [PubMed]

20. Baldinger, A.; Clerdent, L.; Rantanen, J.; Yang, M.; Grohganz, H. Quality by design approach in the optimization of the spray-drying process. Pharm. Dev. Technol. 2012, 17, 389-397. [CrossRef] [PubMed]

21. Paudel, A.; Loyson, Y.; Van den Mooter, G. An investigation into the effect of spray drying temperature and atomizing conditions on miscibility, physical stability, and performance of naproxen-pvp k 25 solid dispersions. J. Pharm. Sci. 2013, 102, 1249-1267. [CrossRef] [PubMed]

22. Lauer, M.E.; Maurer, R.; Paepe, A.T.; Stillhart, C.; Jacob, L.; James, R.; Kojima, Y.; Rietmann, R.; Kissling, T.; van den Ende, J.A.; et al. A miniaturized extruder to prototype amorphous solid dispersions: Selection of plasticizers for hot melt extrusion. Pharmaceutics 2018, 10, 1-25. [CrossRef] [PubMed]

23. Schmitz-Schug, I.; Foerst, P.; Kulozik, U. Impact of the spray drying conditions and residence time distribution on lysine loss in spray dried infant formula. Dairy Sci. Technol. 2013, 93, 443-462. [CrossRef]

24. Petit, J.; Méjean, S.; Accart, P.; Galet, L.; Schuck, P.; Le Floch-Fouéré, C.; Delaplace, G.; Jeantet, R. A dimensional analysis approach for modelling the size of droplets formed by bi-fluid atomisation. J. Food Eng. 2015, 149, 237-247. [CrossRef]

25. Kemp, I.C.; Wadley, R.; Hartwig, T.; Cocchini, U.; See-Toh, Y.; Gorringe, L.; Fordham, K.; Ricard, F. Experimental study of spray drying and atomization with a two-fluid nozzle to produce inhalable particles. Dry. Technol. 2013, 31, 930-941. [CrossRef]

26. Kemp, I.C.; Hartwig, T.; Herdman, R.; Hamilton, P.; Bisten, A.; Bermingham, S. Spray drying with a two-fluid nozzle to produce fine particles: Atomization, scale-up, and modeling. Dry. Technol. 2015, 34, 1243-1252. [CrossRef]

27. Patel, B.B.; Patel, J.K.; Chakraborty, S.; Shukla, D. Revealing facts behind spray dried solid dispersion technology used for solubility enhancement. Saudi Pharm. J. 2015, 23, 352-365. [CrossRef] [PubMed]

28. Arpagaus, C.; Schwartzbach, H. Scale-Up from Bench-Top Research to Laboratory Production; Buchi: Flawil, Switzerland, 2018. 
29. Dobry, D.E.; Settell, D.M.; Baumann, J.M.; Ray, R.J.; Graham, L.J.; Beyerinck, R.A. A model-based methodology for spray-drying process development. J. Pharm. Innov. 2009, 4, 133-142. [CrossRef] [PubMed]

30. Elsayed, K.; Lacor, C. The effect of cyclone inlet dimensions on the flow pattern and performance. Appl. Math. Model. 2011, 35, 1952-1968. [CrossRef]

31. Handscomb, C.S.; Kraft, M. Simulating the structural evolution of droplets following shell formation. Chem. Eng. Sci. 2010, 65, 713-725. [CrossRef]

32. Grasmeijer, N.; de Waard, H.; Hinrichs, W.L.; Frijlink, H.W. A user-friendly model for spray drying to aid pharmaceutical product development. PLoS ONE 2013, 8, 1-11. [CrossRef] [PubMed]

33. Al-Khattawi, A.; Bayly, A.; Phillips, A.; Wilson, D. The design and scale-up of spray dried particle delivery systems. Expert Opin. Drug Deliv. 2017, 15, 1-17. [CrossRef] [PubMed]

34. Conder, E.W.; Cosbie, A.S.; Gaertner, J.; Hicks, W.; Huggins, S.; MacLeod, C.S.; Remy, B.; Yang, B.S.; Engstrom, J.D.; Lamberto, D.J.; et al. The pharmaceutical drying unit operation: An industry perspective on advancing the science and development approach for scale-up and technology transfer. Org. Process Res. Dev. 2017, 21, 420-429. [CrossRef]

35. Paterson, A.H.J.; Brooks, G.F.; Bronlund, J.E.; Foster, K.D. Development of stickiness in amorphous lactose at constant $\mathrm{t}-\mathrm{t}_{\mathrm{g}}$ levels. Int. Dairy J. 2005, 15, 513-519. [CrossRef]

36. Weuts, I.; Kempen, D.; Verreck, G.; Decorte, A.; Heymans, K.; Peeters, J.; Brewster, M.; Van den Mooter, G. Study of the physicochemical properties and stability of solid dispersions of loperamide and peg6000 prepared by spray drying. Eur. J. Pharm. Biopharm. 2005, 59, 119-126. [CrossRef] [PubMed]

37. Lowinger, M.; Baumann, J.; Vodak, D.T.; Moser, J. Practical considerations for spray dried formulation and process development. In Discovering and Developing Molecules with Optimal Drug-Like Properties, 1st ed.; Templeton, A.C., Byrn, S.R., Haskell, R.J., Prisinzano, T.E., Eds.; Springer: New York, NY, USA, 2015; Volume 15, pp. 383-435.

38. Ozmen, L.; Langrish, T.A.G. Comparison of glass transition temperature and sticky point temperature for skim milk powder. Dry. Technol. 2002, 20, 1177-1192. [CrossRef]

39. Walton, D.E. Spray-dried particle morphologies. Dev. Chem. Eng. Miner. Process 2002, 10, 323-348. [CrossRef]

40. Maas, S.G.; Schaldach, G.; Littringer, E.M.; Mescher, A.; Griesser, U.J.; Braun, D.E.; Walzel, P.E.; Urbanetz, N.A. The impact of spray drying outlet temperature on the particle morphology of mannitol. Powder Technol. 2011, 213, 27-35. [CrossRef]

41. Nuzzo, M.; Sloth Overgaard, J.; Bergenståhl, B.; Millqvist-Fureby, A. The morphology and internal composition of dried particles from whole milk-From single droplet to full scale drying. Food Struct. 2017, 13, 35-44. [CrossRef]

42. Walton, D.E. The morphology of spray-dried particles a qualitative view. Dry. Technol. 2000, 18, $1943-1986$. [CrossRef]

43. Cal, K.; Sollohub, K. Spray drying technique. I: Hardware and process parameters. J. Pharm. Sci. 2010, 99, 575-586. [CrossRef] [PubMed]

44. Lin, X.; Hu, Y.; Liu, L.; Su, L.; Li, N.; Yu, J.; Tang, B.; Yang, Z. Physical stability of amorphous solid dispersions: A physicochemical perspective with thermodynamic, kinetic and environmental aspects. Pharm. Res. 2018, 35, 1-18. [CrossRef] [PubMed]

45. Six, K.; Verreck, G.; Peeters, J.; Binnemans, K.; Berghmans, H.; Augustijns, P.; Kinget, R.; Van den Mooter, G. Investigation of thermal properties of glassy itraconazole: Identification of a monotropic mesophase. Thermochim. Acta 2001, 376, 175-181. [CrossRef]

46. Huang, Y.; Dai, W.G. Fundamental aspects of solid dispersion technology for poorly soluble drugs. Acta Pharm. Sin. B 2014, 4, 18-25. [CrossRef] [PubMed]

47. Worku, Z.A.; Aarts, J.; Singh, A.; Van den Mooter, G. Drug-polymer miscibility across a spray dryer: A case study of naproxen and miconazole solid dispersions. Mol. Pharm. 2014, 11, 1094-1101. [CrossRef] [PubMed]

48. Mehta, M.; Kothari, K.; Ragoonanan, V.; Suryanarayanan, R. Effect of water on molecular mobility and physical stability of amorphous pharmaceuticals. Mol. Pharm. 2016, 13, 1339-1346. [CrossRef] [PubMed]

49. Prudic, A.; Ji, Y.; Luebbert, C.; Sadowski, G. Influence of humidity on the phase behavior of api/polymer formulations. Eur. J. Pharm. Biopharm. 2015, 94, 352-362. [CrossRef] [PubMed] 
50. Weuts, I.; Van Dycke, F.; Voorspoels, J.; De Cort, S.; Stokbroekx, S.; Leemans, R.; Brewster, M.E.; Xu, D.; Segmuller, B.; Turner, Y.T.; et al. Physicochemical properties of the amorphous drug, cast films, and spray dried powders to predict formulation probability of success for solid dispersions: Etravirine. J. Pharm. Sci. 2011, 100, 260-274. [CrossRef] [PubMed]

51. Shanbhag, A.; Rabel, S.; Nauka, E.; Casadevall, G.; Shivanand, P.; Eichenbaum, G.; Mansky, P. Method for screening of solid dispersion formulations of low-solubility compounds-miniaturization and automation of solvent casting and dissolution testing. Int. J. Pharm. 2008, 351, 209-218. [CrossRef] [PubMed] 